Manca, Joseph.

\title{
Subject Matter in Italian Renaissance Art: A Study of Early Sources.
}

Medieval and Renaissance Texts and Studies 460. Tempe, AZ: Arizona Center for Medieval and Renaissance Studies, 2015. Pp. xi, $235+22$ b/w ill. ISBN 9780-866698-511-6 (hardcover) US\$60.

Joseph Manca's text is a thoroughly researched resource for those seeking an answer to the question: what did Italian Renaissance people think and know about subject matter in art?

The first chapter is an investigation of iconography and the nonprofessional contemporary audience. Consideration is given here to the lesseducated and how they viewed subject matter in art. Although the general public's opinion was recorded less often than that of the highly literate class, there is much to learn from the former's writing. This social group constituted the largest viewer population in early modern Italy; their perspective is therefore useful in providing information on the range of understanding iconography in the Renaissance.

A breadth of source material is used in this chapter to demonstrate that the majority of common Renaissance people were largely unconcerned with abstruse iconography-rarely is a reference made to subject matter or symbolism in their writing. Of course, this does not mean that iconographic complexity was non-existent or unappreciated. Layered content did exist in pre-modern Italian art. However, it was usually known only to a select few and not a part of the general population's viewing experience.

Chapter 2 is an examination of the learned Renaissance attitude toward subject matter. Here, Manca uses contemporary art history writing to uncover the erudite understanding of iconography in early Italian art. The Renaissance art historian, whose expertise combined contemporary knowledge and oral tradition, was in a unique position to share with the public noteworthy information on subject matter and meaning. Yet an analysis of the writing of Lorenzo Ghiberti, Giorgio Vasari, Ascanio Condivi, and Benvenuto Cellini has revealed that these men were not concerned with deciphering complex iconographical coding. Much of their work is focused instead on exploring the technical and creative ability of the working artist. From this we might conclude that Italian art history literature has little support to offer to the modern scholastic idea that Renaissance people favoured densely symbolic art. 
An in-depth study of the early modern contract is the basis of chapter 3. In exploring the relationship between patron and artist alongside subject matter, Manca is able to show how iconography was produced and consumed in Renaissance Italy. Contractual evidence has indicated that complex instruction from a patron was unusual. In fact, no artist's contract from the Renaissance period encouraged elaborate subject matter. If an artist was granted the opportunity to experiment with iconography, they were excepted from the tradition of making art that conformed to the standard iconographic representation of easy-to-discern subject matter.

Art-historical and theoretical literature is treated in chapter 4, where the Renaissance response to subject matter is explored through the work of Leon Battista Alberti, Leonardo da Vinci, and Ludovico Dolce. Renaissance theory would seem a good source for evidence that early Italian art was embedded with dense meaning. However, Manca's study has revealed that little was done to encourage difficult iconographic invention. For example, in 1557 Ludovico Dolce composed L'Aretino, in which he criticized Michelangelo for painting veiled allegorical iconography because it inhibited the effective communication of a work's narrative.

The fifth and final chapter offers an investigation of the way poetry, ekphrasis, and inscribed art connected image with word for iconographical clarification. Through poetry and ekphrasis, a writer could provide a clear explanation of the detail and narrative force of a work, thereby facilitating the Renaissance audience's viewing experience. A survey of early Italian poetry and ekphrasis can therefore be useful in offering another perspective on the Renaissance experience of understanding subject matter. However, inscribing art was the most direct way to achieve clarity during this period-which is why the practice was popular and often encouraged by clientele.

Modern scholarship has provided a wealth of information on the elucidation and interpretation of iconography in art. However, no guide to understanding meaning existed in pre-modern Italy. Overall, Manca's book does an excellent job of revealing the unique experience of creating, consuming, and comprehending subject matter in the Renaissance. His breadth of evidence and keen analyses show how the early Italian audience depended on straightforward art. Although they sought out work filled with lively action, 
emotional charge, and historical narrative, they nonetheless desired simplicity in subject matter.

JENNIFER STRTAK

Centre for Reformation and Renaissance Studies

Victoria College, University of Toronto

Newman, Karen and Jane Tylus, eds.

\section{Early Modern Cultures of Translation.}

Philadelphia: University of Pennsylvania Press, 2015. Pp. vi, 358. ISBN 978-08122-4740-4 (hardcover) US\$55.

At the outset of their book, about the place and role of translation in the Renaissance, Karen Newman and Jane Tylus ask an obvious question: "Would there have been a Renaissance without translation?" (1). The answer is no, say the essays within. Translations gave the Renaissance its identity as an international, multilingual, and cross-ethnic period of multiple ways of "self-expression" (1). This collection brings together twelve essays and a coda, offering a wealth of new material and original re-interpretations of translation as both philological practice and a metaphorical transmission of cultural practices, as Peter Burke illustrates in his analysis of the circulation of the language of architecture and illustrations that enhance the reception of these texts across Renaissance Europe.

Taken together, the essays in this book analyze the concept of difference, treating it as a key to understanding translation as a revisionary narrative about early modernity - in contrast with the story about the "glorified individual" (1), which for a long time determined how scholars wrote about the Renaissance. The contrast is evident not just in approaches but also in the methodologies, places, and languages that extend the idea of translation as a cultural practice beyond Western Europe. The idea is not all that new, but the case studies collected in this volume emphasize comparativism as a productive angle from which to examine the role of translation in shaping differences and diversities within the early modern world. Yet even a volume that maps its thematic territory as broadly as this one does cannot be as comprehensive as one thinks. The idea of difference as a distinctive way to analyze the cultural work of translation 